\title{
Special Issue Annex
}

\section{The GLOBE Student project: Methods and sample structures}

\author{
Tomaž Čater, Rainhart Lang, Erna Szabo*
}

\section{Research instrument}

The research instrument builds on the GLOBE Beta version questionnaire for national culture and leadership scales (House et al. 2004). Some modifications were made to adapt it to a student population. The scale on values or factors for critical management decisions originates from the questionnaire used in the third phase of the initial GLOBE project (House et al. 2013). In addition, the GLOBE Student researchers developed specific scales on their own, in particular concerning the influence of socialisation agents. The complete questionnaire is described in Čater and Lang (2011).

For all scales the respondents were asked to express their agreement with given statements using a seven-point Likert-type scale. Most cultural items had the anchors 1 = "strongly disagree" and 7 = "strongly agree", while some anchors were explicitly specified, such as $1=$ "individual interests" and $7=$ "collective interests". The leadership scales ranged from $1=$ "greatly inhibits" to $7=$ "contributes greatly", the scales for value preferences in decisions from $1=$ "none" to 7 = "most important", and the scales for the influence of socialisation agents from 1 = "not at all" to 7 = "very strong".

Variables were measured either in a positive direction or were appropriately recoded later on. The leadership scales took the form of leadership attributes that inhibit (options 1-3) or contribute to the perception of a good and effective leader (options 5-7), with a neutral point of 4 ("has no impact"). The scales for value preferences in critical decisions and the influence of role models for leadership stereotypes ranged from no impact/influence (1) to strong impact/influence. Demographic questions were of open nature.

Tomaž Čater, Ph.D., Associate Professor, Faculty of Economics, University of Ljubljana, Slovenia. Main research interests: Corporate strategy, business strategy, environmental strategy, competitive advantage, intellectual capital. Corresponding Address: tomaz.cater@ef.uni-lj.si

Rainhart Lang, Full Professor, Department of Economics \& Business Administration, Chemnitz University of Technology, Germany. Main research interests: Leadership theories and cross cultural aspects of management and leadership, organisational change and transformation, managerial professions. Corresponding Address: r.lang@wirtschaft.tu-chemnitz.de

Erna Szabo, Associate Professor, Department of International Management, Johannes Kepler University Linz, Austria. Main research interests: Participative and ethical leadership, cultural intelligence, crossvergence, erosion of trust. Corresponding Address: erna.szabo@jku.at 
The scales were calculated and tested according to the original GLOBE syntax, in order to allow for a comparison with the middle manager results of the initial GLOBE project. Moreover, we tried to optimize the scales by partly replacing items.

\section{Research population}

The research population consists of business and engineering students from the following seven Central and Eastern European countries: Austria, Czech Republic, Germany, Poland, Romania, Slovakia and Slovenia. It was our goal to secure a sample of at least 300 students from each country. Since we wanted to test the differences between business and engineering students as well as the differences between undergraduate (bachelor students and students in lower semesters of diploma programmes) and graduate/postgraduate (master students and students in higher semesters of diploma programmes) students, we employed a stratified sampling strategy. The following four stratums had been defined in advance: (1) undergraduate business students, graduate/postgraduate business students, (3) undergraduate engineering students, and (4) graduate/postgraduate engineering students. It was our goal to include a minimum of 75 students from each country ( $25 \%$ of the students) in each of the four stratums.

\section{Data collection}

Data were collected between January 2008 and April 2010. The data collection periods varied between the seven countries as a result of different semester schedules and the fact that some countries joined the project at a later point in time. The printed questionnaires, along with instructions on how to fill them out and the assurance of anonymity, were distributed to students before lectures. The students who agreed to participate in the study then took the questionnaires home and returned them at the beginning of their next lecture (usually one week later). This enabled students to answer the questionnaires when they had time, i.e. without any time pressure. Out of 3740 questionnaires distributed in the seven participating countries, 2356 were returned to the researchers satisfactorily completed (i.e. without any missing values or less than $2 \%$ of missing values), representing a response rate of $63.0 \%$. Data were processed by using SPSS 17 statistical software.

\section{Sample structure}

In the following paragraphs we present the structure of our final student sample. Figure 1 shows the distribution between the countries the students study in. As can be seen, the largest number of students in our sample is from Romania (429 students or $18.2 \%$ ), followed by Germany (345 students or $14.6 \%$ ), Slovakia (339 students or 14.4\%), the Czech Republic (324 students or 13.8\%), Austria 
(314 students or 13.3\%), Poland (305 students or 12.9\%) and Slovenia (300 students or $12.7 \%)$.

Figure: Country of study

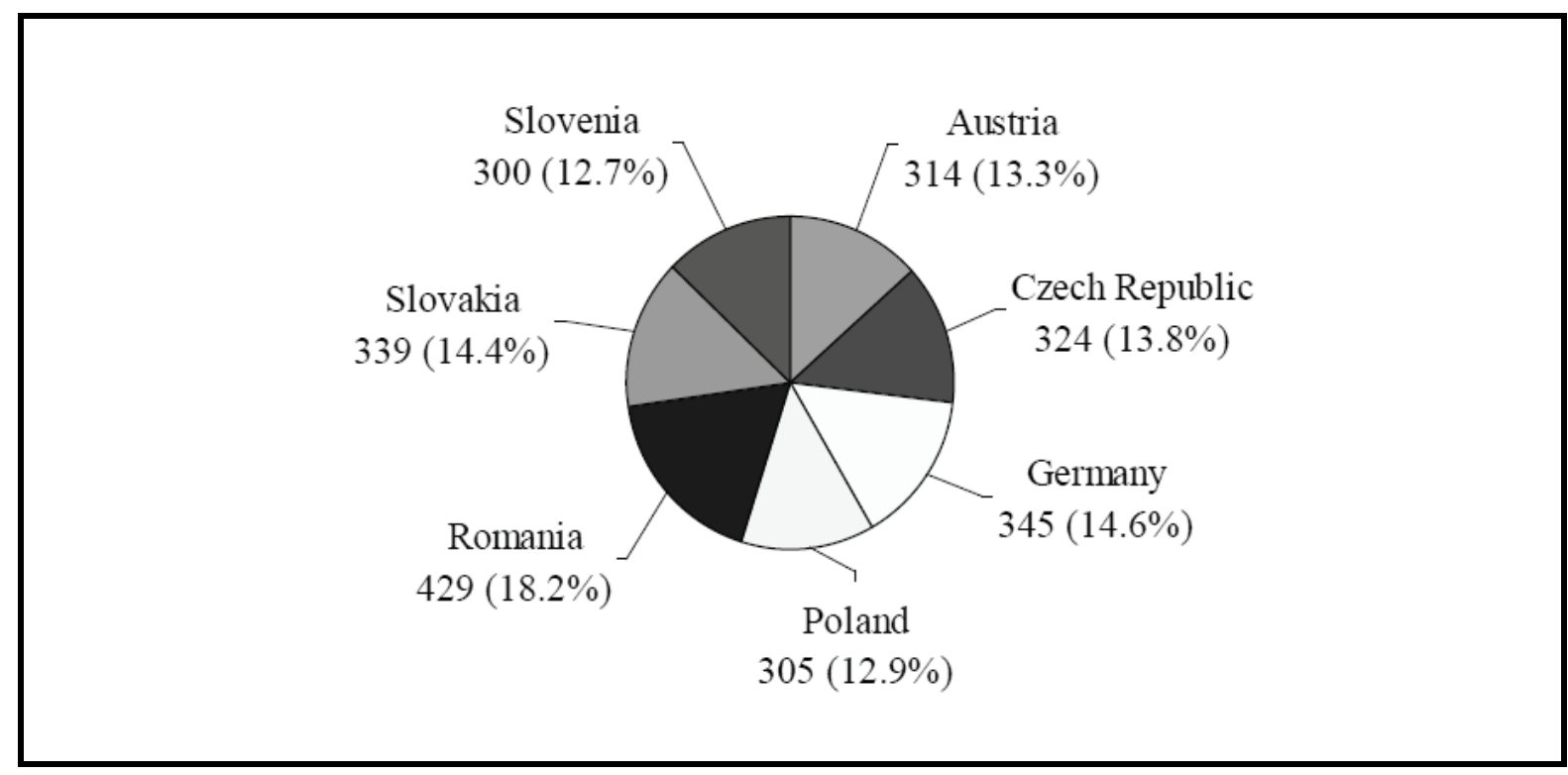

The structure of the final sample according to the students' gender (see Table 1) shows that male $(52.6 \%)$ and female $(47.4 \%)$ students are relatively equally represented in the sample. However, the gender split differs somewhat between countries. In the Czech Republic, Germany and Slovakia there is almost no difference between the number of male and female students in the sample. In contrast, the Austrian (54.8\% vs. $45.2 \%)$, Polish $(60.0 \%$ vs. $40.0 \%)$ and Slovenian (60.3\% vs. $37.7 \%)$ samples are characterized by a larger proportion of male students, which is primarily due to the fact that the majority of engineering students in these countries are male. In Romania the picture is exactly the opposite, i.e. there are more female than male students in the sample $(55.7 \%$ vs. $44.3 \%)$. 
Table 1: Students' gender distribution

\begin{tabular}{|l|c|c|c|c|c|c|}
\hline \multirow{2}{*}{ Country } & \multicolumn{2}{|c|}{ Male } & \multicolumn{2}{c|}{ Female } & \multicolumn{2}{c|}{ Total } \\
\cline { 2 - 7 } & $\mathbf{N}$ & $\mathbf{\%}$ & $\mathbf{N}$ & $\mathbf{\%}$ & $\mathbf{N}$ & $\mathbf{\%}$ \\
\hline Austria & 172 & 54.8 & 142 & 45.2 & 314 & 100.0 \\
\hline $\begin{array}{l}\text { Czech } \\
\text { Republic }\end{array}$ & 167 & 51.5 & 157 & 48.5 & 324 & 100.0 \\
\hline Germany & 168 & 49.4 & 172 & 50.6 & 340 & 100.0 \\
\hline Poland & 183 & 60.0 & 122 & 40.0 & 305 & 100.0 \\
\hline Romania & 190 & 44.3 & 239 & 55.7 & 429 & 100.0 \\
\hline Slovakia & 176 & 51.9 & 163 & 48.1 & 339 & 100.0 \\
\hline Slovenia & 181 & 60.3 & 119 & 39.7 & 300 & 100.0 \\
\hline Total & 1237 & 52.6 & 1114 & 47.4 & $2351^{1)}$ & 100.0 \\
\hline
\end{tabular}

Note: ${ }^{1)}$ missing values $=5$.

The average age of all students in the sample is 22.6 years, with a standard deviation of 3.4 years (see Table 2). At the time of data collection, the youngest students were 18 years old, while the oldest student was 54 . The highest average age of students can be observed in Austria (24.1 years), while the lowest average age of students is reported in Slovakia (21.7 years) and the Czech Republic (21.8 years).

Table 2: Students' age distribution

\begin{tabular}{|l|c|c|c|c|c|c|c|c|}
\hline & $\begin{array}{c}\text { Aust- } \\
\text { ria }\end{array}$ & $\begin{array}{c}\text { Czech } \\
\text { Re- } \\
\text { public }\end{array}$ & $\begin{array}{c}\text { Ger- } \\
\text { many }\end{array}$ & $\begin{array}{c}\text { Po- } \\
\text { land }\end{array}$ & $\begin{array}{c}\text { Roma- } \\
\text { nia }\end{array}$ & $\begin{array}{c}\text { Slova- } \\
\text { kia }\end{array}$ & $\begin{array}{c}\text { Slove- } \\
\text { nia }\end{array}$ & Total \\
\hline $\mathrm{N}$ & 313 & 324 & 340 & 305 & 429 & 339 & 300 & $2350^{l)}$ \\
\hline Mean & 24.1 & 21.8 & 22.0 & 23.0 & 22.3 & 21.7 & 23.3 & 22.6 \\
\hline $\begin{array}{l}\text { Std. } \\
\text { dev. }\end{array}$ & 4.2 & 3.5 & 3.1 & 3.2 & 2.9 & 2.0 & 4.1 & 3.4 \\
\hline
\end{tabular}

Note: ${ }^{1)}$ missing values $=6$.

With regard to the field of study, we can report that the group of business economics students is homogenous because these students all come from business schools. In contrast, the group of engineering students is more heterogeneous since it includes students from a variety of different faculties, including mechanical engineering, electrical engineering, and computer and information science. Table 3 shows that the largest number of students in business economics (1175 students or 50.1\%), followed by 1085 engineering 
students $(46.3 \%$ of the sample). A total of 66 students $(2.8 \%$ of the sample) are studying both business and engineering, while 18 students ( $0.8 \%$ of the sample) come from other study fields. An almost equal distribution between business and engineering students can be found in the Polish (50.5\% vs. $49.5 \%)$ and Czech (50.6\% vs. $49.4 \%$ ) samples, while the largest disproportion is in the Austrian (62.5\% of business students vs. only $35.3 \%$ of engineering students) and Romanian (only $39.2 \%$ of business students vs. $60.8 \%$ of engineering students) samples.

Table 3: Field of study

\begin{tabular}{|c|c|c|c|c|c|c|c|c|c|c|}
\hline \multirow[t]{2}{*}{ Country } & \multicolumn{2}{|c|}{ Business } & \multicolumn{2}{|c|}{ Engineering } & \multicolumn{2}{|c|}{$\begin{array}{c}\text { Business }+ \\
\text { Engineering }\end{array}$} & \multicolumn{2}{|c|}{$\begin{array}{l}\text { Other } \\
\text { Fields }\end{array}$} & \multicolumn{2}{|c|}{ Total } \\
\hline & $\mathbf{N}$ & $\%$ & $\mathbf{N}$ & $\%$ & $\mathbf{N}$ & $\%$ & $\mathbf{N}$ & $\%$ & $\mathbf{N}$ & $\%$ \\
\hline tive & 195 & 62.5 & 10 & 252 & & 2 & 0 & 0.0 & 312 & 100.0 \\
\hline $\begin{array}{l}\text { Czec } \\
\text { Repu }\end{array}$ & 164 & 50.6 & 50 & 49 & & 0 . & 0 & 0 & 324 & 100.0 \\
\hline Germa & 0. & + & 133 & 39.7 & 24 & 7.2 & 16 & & 335 & .0 \\
\hline Poland & 154 & 50.5 & 151 & 49.5 & & 0.0 & 0 & 0.0 & 305 & 100.0 \\
\hline Romania & 168 & 39.2 & 261 & 60.8 & 0 & 0.0 & 0 & 0 & 429 & 100.0 \\
\hline Slovakia & 182 & 53.7 & 136 & 40.1 & 19 & 5.6 & 2 & 0.6 & 339 & 100.0 \\
\hline Slovenia & 150 & 50.0 & 134 & 44.7 & 16 & 5.3 & 0 & 0.0 & 300 & 100.0 \\
\hline Total & 1175 & 50.1 & 1085 & 46.3 & 66 & 2.8 & 18 & 0.8 & $2344^{1)}$ & 100.0 \\
\hline
\end{tabular}

Note: ${ }^{1)}$ missing values $=12$.

As regards the level of study (see Table 4) there are 63.6\% undergraduate and $36.4 \%$ graduate/postgraduate students in the sample. We should mention that some students did not enter this information, which resulted in 54 missing values. The largest disproportion between the two cohorts can be found in the Polish (all students were undergraduate students), German (83.2\% undergraduate vs. $16.8 \%$ graduate/postgraduate students) and Romanian (64.8\% undergraduate vs. $35.2 \%$ graduate/postgraduate students) samples, while the Slovenian sample shows a perfectly balanced distribution between undergraduate and graduate/postgraduate students (i.e. exactly $50.0 \%$ in each group). 
Table 4: Level of study

\begin{tabular}{|l|c|c|c|c|c|c|}
\hline \multirow{2}{*}{ Country } & \multicolumn{2}{|c|}{ Undergraduate } & \multicolumn{2}{|c|}{ Graduate/Postgraduate } & \multicolumn{2}{|c|}{ Total } \\
\cline { 2 - 7 } & $\mathbf{N}$ & $\mathbf{\%}$ & $\mathbf{N}$ & $\mathbf{\%}$ & $\mathbf{N}$ & $\mathbf{\%}$ \\
\hline Austria & 166 & 55.5 & 133 & 44.5 & 299 & 100.0 \\
\hline $\begin{array}{l}\text { Czech } \\
\text { Republic }\end{array}$ & 131 & 45.2 & 159 & 54.8 & 290 & 100.0 \\
\hline Germany & 283 & 83.2 & 57 & 16.8 & 340 & 100.0 \\
\hline Poland & 305 & 100.0 & 0 & 0.0 & 305 & 100.0 \\
\hline Romania & 278 & 64.8 & 151 & 35.2 & 429 & 100.0 \\
\hline Slovakia & 152 & 44.8 & 187 & 55.2 & 339 & 100.0 \\
\hline Slovenia & 150 & 50.0 & 150 & 50.0 & 300 & 100.0 \\
\hline Total & 1465 & 63.6 & 837 & 36.4 & $2302^{1)}$ & 100.0 \\
\hline
\end{tabular}

Note: ${ }^{1)}$ missing values $=54$.

Finally, we also analyzed the sample with respect to two important variables related to the students' future careers, namely their interest in working as managers and/or entrepreneurs (see Table 5). Overall, 69.7\% of the students marked their interest in a management career, while the percentage of students interested in an entrepreneurship career is somewhat lower $(60.4 \%)$. We found today's students to be the most interested in a management career in Slovakia (79.6\%), Poland (78.4\%) and Austria (78.1\%), while the lowest percentage of students interested in a management career was found in the Slovenia data $(49.0 \%)$. The interest in an entrepreneurship career was strongest in Romania $(73.9 \%)$ and Poland $(72.5 \%)$, whereas the weakest interest in becoming entrepreneurs was indicated by the Austrian students (45.9\%). 
Table 5: Students' interest in a management and/or entrepreneurship career

\begin{tabular}{|c|c|c|c|c|}
\hline \multirow[t]{2}{*}{ Country } & \multicolumn{2}{|c|}{$\begin{array}{c}\text { Interest in Management } \\
\text { Career }\end{array}$} & \multicolumn{2}{|c|}{$\begin{array}{c}\text { Interest in } \\
\text { Entrepreneurship Career }\end{array}$} \\
\hline & $\mathbf{N}$ & $\%$ & $\mathbf{N}$ & $\%$ \\
\hline Austria & 242 & 78.1 & 141 & 45.9 \\
\hline Czech Republic & 231 & 71.3 & 174 & 53.7 \\
\hline Germany & 215 & 64.4 & 175 & 52.4 \\
\hline Poland & 239 & 78.4 & 221 & 72.5 \\
\hline Romania & 288 & 67.1 & 317 & 73.9 \\
\hline Slovakia & 270 & 79.6 & 225 & 66.4 \\
\hline Slovenia & 147 & 49.0 & 158 & 52.7 \\
\hline Total & $1632^{1)}$ & 69.7 & $1411^{2)}$ & 60.4 \\
\hline
\end{tabular}

Notes: ${ }^{1)}$ missing values $=16 ;{ }^{2)}$ missing values $=18$.

\section{References}

Čater, T./Lang, R. (eds.) (2011): Values and leadership expectations of future managers from transforming societies, Organisationswissenschaftliche Schriftenreihe der TU Chemnitz, No. 16, August 2011. Chemnitz: Chemnitz University of Technology. (http://www.tuchemnitz.de/wirtschaft/bw15/forschung/schriften/doc/16.pdf).

House, R.J./Dorfman, P.W./Javidan, M./Hanges, P.J./Sully de Luque, M.F. (2013): Strategic leadership across cultures: The GLOBE study of CEO leadership behavior and effectiveness in 24 countries. Thousand Oaks: Sage.

House, R.J./Hanges, P.J./Javidan, M./Dorfman, P.W./Gupta, V. (eds.) (2004): Culture, leadership, and organizations: The GLOBE study of 62 societies. Thousand Oaks: Sage. 